\title{
National trends in rates of death and hospital admissions related to acute myocardial infarction, heart failure and stroke, 1994-2004
}

\author{
Jack V. Tu MD PhD, Lorelei Nardi MSc, Jiming Fang PhD, Juan Liu MD, Laila Khalid MD, \\ Helen Johansen PhD, for the Canadian Cardiovascular Outcomes Research Team
}

An abridged version of this article appeared in the June 23 issue of $C M A J$

$\infty \infty$

See related commentary by Capewell and O'Flaherty, page 1283

\section{ABSTRACT}

Background: Rates of death from cardiovascular and cerebrovascular diseases have been steadily declining over the past few decades. Whether such declines are occurring to a similar degree for common disorders such as acute myocardial infarction, heart failure and stroke is uncertain. We examined recent national trends in mortality and rates of hospital admission for these 3 conditions.

Methods: We analyzed mortality data from Statistic Canada's Canadian Mortality Database and data on hospital admissions from the Canadian Institute for Health Information's Hospital Morbidity Database for the period 1994-2004. We determined age- and sex-standardized rates of death and hospital admissions per 100000 population aged 20 years and over as well as in-hospital case-fatality rates.

Results: The overall age- and sex-standardized rate of death from cardiovascular disease in Canada declined $30.0 \%$, from 360.6 per 100000 in 1994 to 252.5 per 100000 in 2004. During the same period, the rate fell $38.1 \%$ for acute myocardial infarction, $23.5 \%$ for heart failure and $28.2 \%$ for stroke, with improvements observed across most age and sex groups. The age- and sex-standardized rate of hospital admissions decreased $27.6 \%$ for stroke and $27.2 \%$ for heart failure. The rate for acute myocardial infarction fell only $9.2 \%$. In contrast, the relative decline in the inhospital case-fatality rate was greatest for acute myocardial infarction $(33.1 \% ; p<0.001)$. Much smaller relative improvements in case-fatality rates were noted for heart failure $(8.1 \%)$ and stroke $(8.9 \%)$.

Interpretation: The rates of death and hospital admissions for acute myocardial infarction, heart failure and stroke in Canada changed at different rates over the 10-year study period. Awareness of these trends may guide future efforts for health promotion and health care planning and help to determine priorities for research and treatment.

Une version française de ce résumé est disponible à l'adresse www.cmaj.ca/cgi/content/full/cmaj.081197/DC2

CMAJ 2009;180(13):E120-E7
$\mathrm{C}$ ardiovascular disease, including stroke, is the leading cause of death globally. Therefore, changes in the incidence and mortality of these disorders have a major impact on the overall health of a country's population and on the health care system. ${ }^{1}$ Rates of death from cardiovascular and cerebrovascular disease have been steadily declining in Western Europe and North America for the past 3 decades. ${ }^{2,3}$ Whether this decline is occurring to a similar degree for common conditions such as acute myocardial infarction, heart failure and stroke is uncertain. Although these 3 conditions are associated with several common risk factors, the relative importance of risk factors such as smoking, hypertension and hyperlipidemia differs between them. ${ }^{4}$ Furthermore, the rate of new therapeutic advances for these conditions has varied in both the acute, in-hospital setting and in the outpatient setting, where primary and secondary prevention of events occurs.

A comparative evaluation of recent population-based trends in incidence and mortality would provide an assessment of the relative progress achieved in preventing and treating these important conditions. Furthermore, the substantial economic impact of cardiovascular disease, including stroke, on the health care system - estimated at $\$ 18$ billion per year in direct and indirect costs in Canada in $1998^{5}$ - underscores the need for continued monitoring of cardiovascular disease and treatment outcomes. A study of temporal trends could also help guide future health promotion activities and health care planning.

We conducted a study of recent trends in the rates of death and hospital admissions for acute myocardial infarction, heart failure and stroke in Canada from 1994 to 2004. We also studied whether changes in these trends occurred at similar rates in younger and older Canadians and in both sexes.

From the Institute for Clinical Evaluative Sciences (Tu, Nardi, Fang, Liu, Khalid), Toronto, Ont.; the Division of Cardiology, Schulich Heart Centre, Sunnybrook Health Sciences Centre, University of Toronto (Tu), Toronto, Ont.; and the Health Analysis Division, Statistics Canada (Johansen), Ottawa, Ont. 


\section{Methods}

\section{Data collection}

\section{Mortality data}

We obtained data on deaths from Jan. 1, 1994, to Dec. 31, 2004, from the Canadian Mortality Database, Statistics Canada's national administrative death registry. This database receives information annually from all provincial and territorial registries of vital statistics on the cause of all deaths. ${ }^{6}$ We used International Classification of Diseases (ICD) codes from the ninth and tenth revisions ${ }^{7,8}$ to identify deaths for which the most responsible cause was cardiovascular disease. We used the ICD-10 codes because Canada switched from the ICD-9 to the ICD-10 coding system in 2000 for the coding of death certificates. We classified cardiovascular deaths overall and specifically for acute myocardial infarction, heart failure and stroke using the ICD-9 and ICD10 codes shown in Appendix 1 (available at www.cmaj.ca/cgi /content/full/cmaj.081197/DC3). ICD codes for stroke are considered part of the overall category of cardiovascular disease; thus, our discussions of trends in the rates of death and hospital admissions for cardiovascular disease include stroke.

We determined the overall crude population-based rate of death per 100000 population aged 20 years and over for each year by dividing the number of deaths for each condition by the size of the corresponding Canadian population, as determined from the Canadian census. In addition, we calculated the age- and sex-standardized rate of death through direct standardization to the 1991 Canadian population, the standard reference population recommended by Health Canada for disease surveillance. ${ }^{9}$ We also calculated the rates of death for 4 age groups (20-49 years, 50-64, 65-74, and 75 and older) and for men and women.

Hospital admission and in-hospital case-fatality data We determined the rates of hospital admissions from Apr. 1, 1994, to Mar. 31, 2004, because of acute myocardial infarction, heart failure and stroke using codes for the most responsible diagnosis (that which contributed the most to a patient's length of stay) recorded in the Canadian Institute for Health

Table 1: Trends in the rates of death, hospital admissions and in-hospital case fatality associated with acute myocardial infarction, heart failure and stroke in Canada, 1994-2004

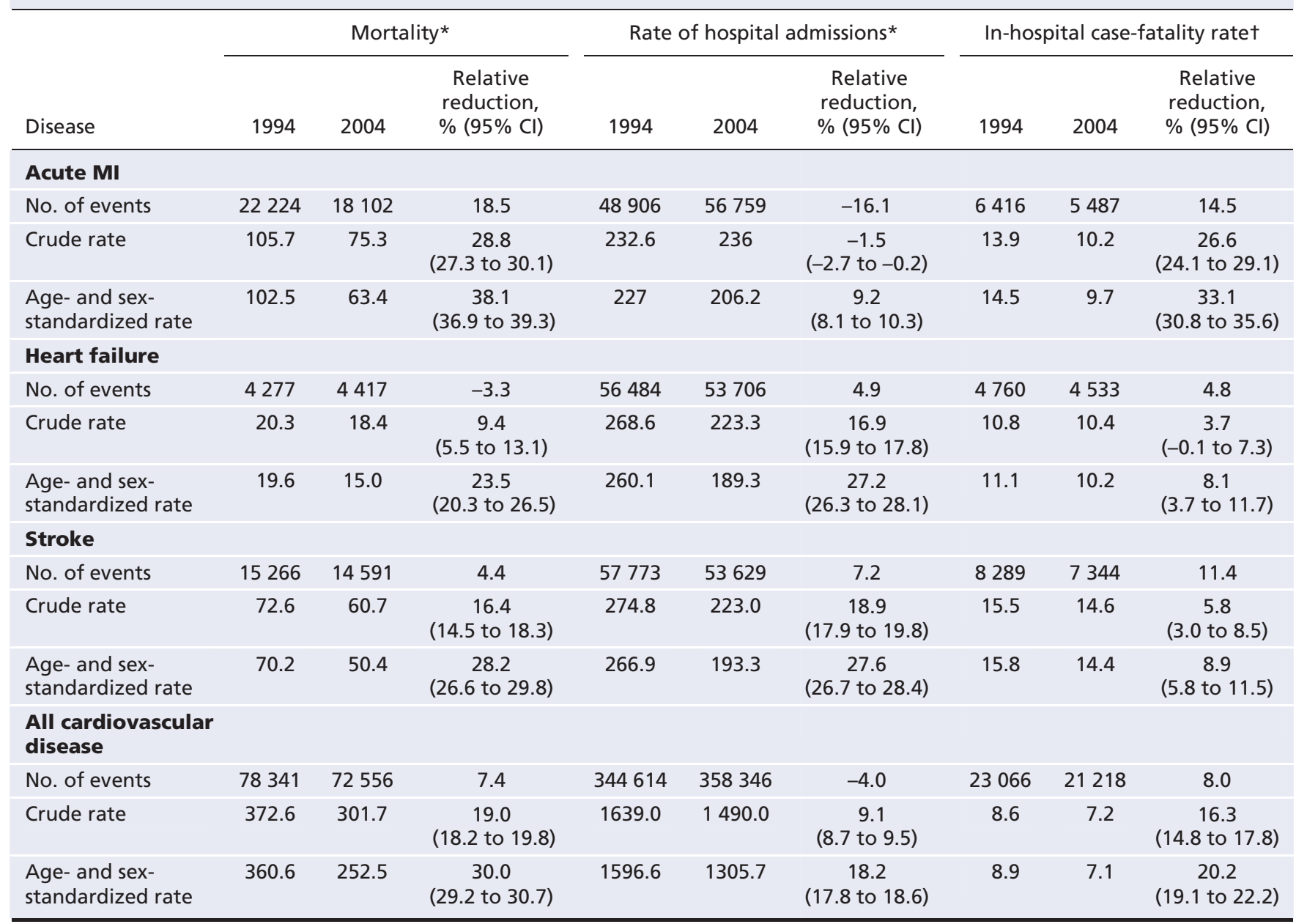

Note: $\mathrm{Cl}=$ confidence interval, $\mathrm{MI}=$ myocardial infarction.

*Unless stated otherwise. Rates of death and hospital admissions are per 100000 population aged 20 years and over; age- and sex-standardized rates are standardized to the 1991 Canadian census population.

tIn-hospital case-fatality rates are age- and sex-adjusted with the population of all cases being the reference population 
Information's Hospital Morbidity Database. We used the ICD-9 and ICD-10 codes shown in Appendix 1 (available at www.cmaj.ca/cgi/content/full/cmaj.081197/DC3) to classify the hospital admissions by condition. Previous studies have confirmed the high accuracy rate of coding of cardiovascular diseases and stroke in these databases..$^{10-14}$

To avoid double-counting of transferred patients, we created episodes of care whereby patients with the same encrypted health card number who were discharged from one institution and then admitted to another on the same day were assumed to have been transferred. We counted these patients only once. We calculated crude as well as age- and sex-standardized rates of hospital admissions per 100000 population aged 20 and over. We also calculated crude, age- and sex-adjusted inhospital case-fatality rates based on episodes of care among patients admitted with these conditions over this period.

\section{Statistical analysis}

We determined 95\% confidence intervals (CIs) for the rates of death and hospital admissions and in-hospital case-fatality rates using statistical boot-strapping techniques. We selected a random sample of patients from the study cohort of the same size as the original study cohort. Each patient could be selected once, multiple times, or not at all in the random sample. We then calculated the corresponding rates (e.g., rates of death) using the sample data set. After repeating the process 1000 times, the $95 \%$ CIs of the boot-strapped samples were obtained from the 2.5 th and the 97.5 th percentiles of the 1000 re-estimated rates.

\section{Ethical approval}

The study was approved by the research ethics board at the Sunnybrook Health Sciences Centre.

\section{Results}

\section{Mortality}

The overall trends in the rates of death for acute myocardial infarction, heart failure and stroke are shown in Table 1 and Figure 1. The population of Canada increased $14.4 \%$, from 21 million people aged 20 and over in 1994 to 24 million in 2004. The all-cause mortality in Canada decreased from 933.1 per 100000 in 1994 to 792.4 in 2004, a relative decline of $15.1 \%$ (95\% CI 14.6\%-15.5\%). The overall age- and sex-standardized rate of death from cardiovascular disease declined $30.0 \%$ (95\% CI 29.2\%-30.7\%), from 360.6 per 100000 population aged 20 and over in 1994 to 252.5 per 100000 in 2004. This represents an average annual rate of decline of $2.7 \%$. The greatest decline was observed for deaths from acute myocardial infarction, which fell $38.1 \%$ (95\% CI 36.9\%-39.3\%). This drop accounted for about $70 \%$ of the overall decrease in the number of deaths from cardiovascular disease. The age- and sex-standardized rate of death decreased $28.2 \%$ (95\% CI 26.6\%-29.8\%) for stroke and $23.5 \%$ (95\% CI $20.3 \%-26.5 \%$ ) for heart failure.

Trends in mortality rates by age and sex groups are shown in Table 2. We observed decreases in the mortality rates for all 3 conditions in most age and sex groups. Historically, rates of death from cardiovascular disease in Canada have been higher among men than among women. In 1994, men represented slightly more than half $(50.7 \%)$ of all cardiovascular deaths in Canada. By 2000, however, more women than men had died of cardiovascular disease. By 2004, 50.5\% of all cardiovascular deaths in Canada were occurring in women. For all 3 conditions, deaths occurred predominantly among people aged 75 and over regardless of their sex (Table 2), although many deaths from acute myocardial infarction also occurred in younger groups. More men than women died of acute myocardial infarction; the opposite was true for heart failure and stroke.

\section{Rates of hospital admission}

The overall rate of hospital admissions in Canada for any conditions declined $13.1 \%$ between 1995 and 2004. ${ }^{15}$ The trend in hospital admissions because of heart failure and stroke declined steadily at similar rates, beginning in 1995 for stroke and in 1997 for heart failure (Figure 2). Overall, the rates of hospital admissions declined $27.2 \%$ (95\% CI $26.3 \%$ $28.1 \%$ ) for heart failure and $27.6 \%$ (95\% CI $26.7 \%-28.4 \%$ ) for stroke between 1994 and 2004 (Table 1).

In contrast, the rates for acute myocardial infarction were more varied. They declined from 1996 to 1998, increased in 1999, peaked in 2000 and declined modestly thereafter (Figure 2). The absolute number of hospital admissions because of acute myocardial infarction increased 16.1\%, from 48906

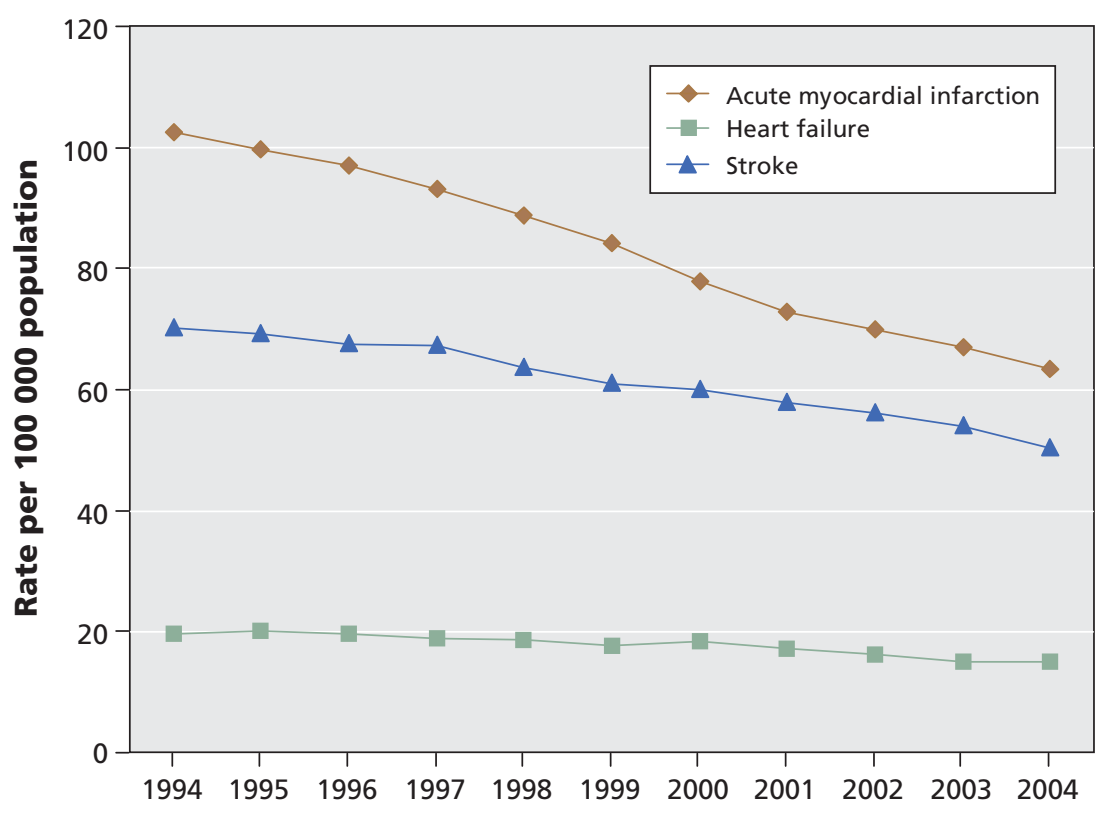

Figure 1: Age- and sex-standardized rates of death from acute myocardial infarction, heart failure and stroke per 100000 population aged 20 and over in Canada, 1994-2004. Rates are standardized to the Canadian 1991 census population. 
in 1994 to 56759 in 2004, whereas the overall age- and sexstandardized rate declined $9.2 \%$ (95\% CI 8.1\%-10.3\%).

We observed a shift in cardiovascular-related hospital admissions between 1994 and 2004 to an ever-increasing proportion of elderly patients for all 3 conditions (Table 3 ). In 2004, the median age of patients admitted because of acute myocardial infarction was 71 , compared with 75 for those with stroke and 79 for those with heart failure. Men accounted for about two-thirds of all admissions because of acute myocardial infarction throughout the study period. The proportion of admissions because of heart failure and stroke remained similar between the 2 sexes. For all 3 conditions, women were more likely than men to be admitted to hospital at a later age, with a difference of 11 years for acute myocardial infarction and 5 years for both heart failure and stroke in 2004.

\section{In-hospital case-fatality rates}

We observed a striking decline of $33.1 \%$ (95\% CI 30.8\%$35.6 \%$ ) in the age- and sex-adjusted in-hospital case-fatality rate for acute myocardial infarction, from 14.5\% in 1994 to $9.7 \%$ in $2004(p<0.001)$ (Table 1 and Figure 3). In contrast, more modest improvements were seen in the case-fatality rates for heart failure and stroke. The ratio of the number of patients who died during their hospital stay to the number who died of a cardiovascular cause as recorded on the death certificate was slightly less than one-third (Table 1). This suggested that much of the improvement in overall rates of death from cardiovascular disease were due to a decline in out-of-hospital deaths.

\section{Interpretation}

The decade of 1994 to 2004 was one of considerable invest-

Table 2: Age- and sex-specific rates of death by cardiovascular disease per 100000 population aged 20 and over in Canada, 1994-2004

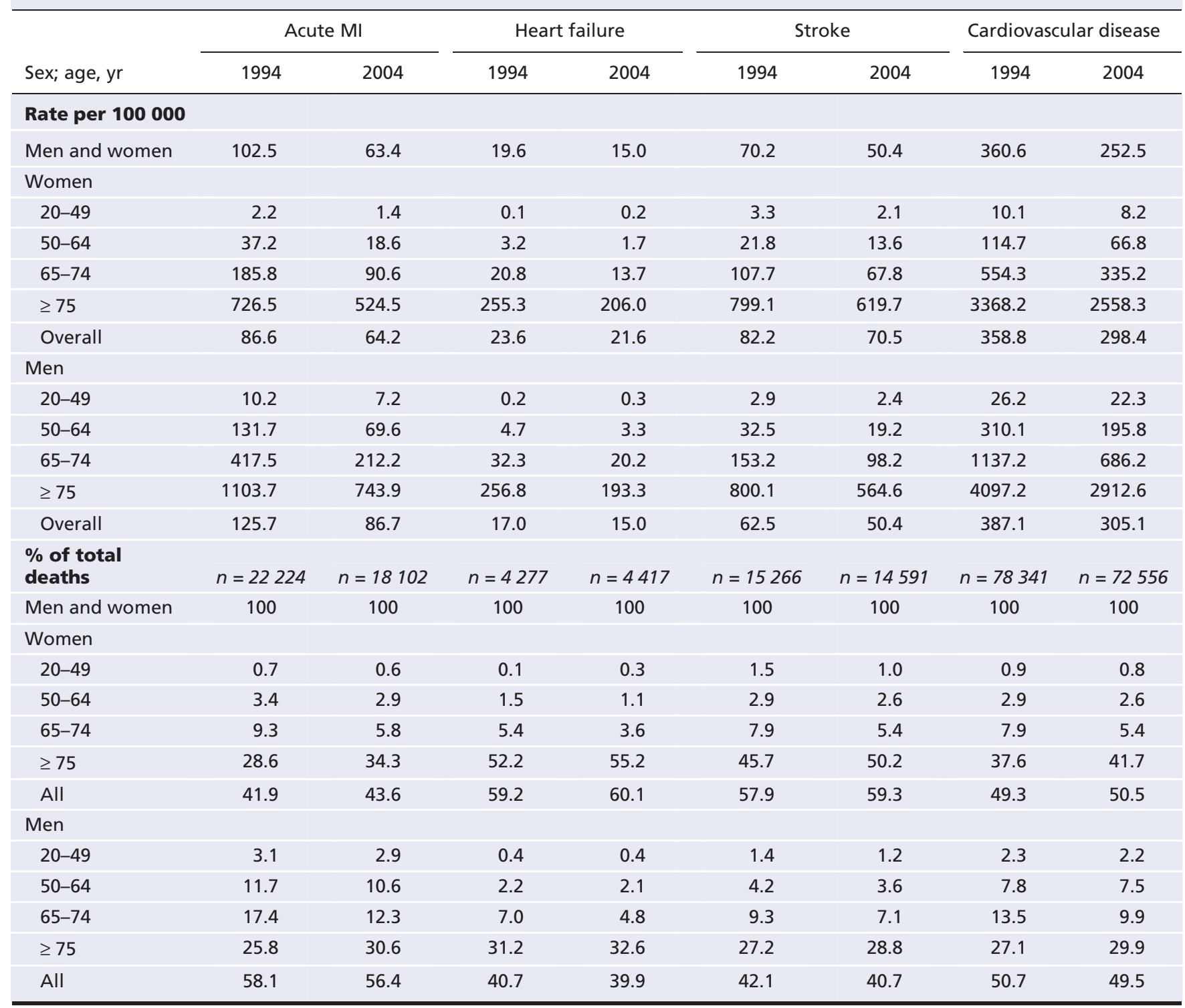

Note: $\mathrm{MI}=$ myocardial infarction.

*All mortality rates are per 100000 population 
ment and improvement in Canada in both the prevention and treatment of cardiovascular disease. We observed major reductions in all-cause mortality related to cardiovascular disease, including stroke, in Canada during this period, with an average annual rate of decline of about $3 \%$. Similar annual rates of decline have been reported in the United States and in many Western European countries. ${ }^{2,16}$ Much of the improvement in Canada was driven by declines in the rate of death from acute myocardial infarction, although the rates of death from heart failure and stroke also decreased significantly. In addition, we found increasing proportions of elderly Canadians being admitted to hospital because of cardiovascular disease and stroke and, for the first time, more women than men dying of cardiovascular disease. These data have important clinical and policy implications for practitioners and health system planners.

A key finding from our analysis was the rapid decline in the rate of death from acute myocardial infarction. Although it is not possible in Canada to distinguish out-ofhospital deaths from in-hospital deaths based on coding data from death certificates alone, we observed that about 4000 fewer Canadians died from acute myocardial infarction in 2004 than in 1994 despite a 16\% increase in the absolute number of patients admitted to hospital because of acute myocardial infarction and a $14 \%$ increase in the size of the adult population in Canada. Our findings suggest that there were significant declines in the number of out-of-hospital deaths from acute myocardial infarction. This improvement could reflect declines in key risk factors for myocardial infarction, such as a reduction in the proportion of people in Canada aged 15 and over who smoke from $25 \%$ in 1999 to $20 \%$ in 2004 , and better control of lipid levels and associated coronary plaque stabilization through increasing rates of statin use in Canada. ${ }^{17,18}$

We also noted that the rate of hospital admissions because of acute myocardial infarction appeared to be declining between 1996 and 1998 but then rose again to a plateau in 2000 followed by a modest decline thereafter. The period from 1998 to 2000 coincided with the introduction of highly sensitive cardiac troponin assays in Canadian hospitals and a change in the European Society of Cardiology/American College of Cardiology epidemiological definition of myocardial infarction in 2000; 19 these changes probably resulted in some patients being classified as having an acute population.

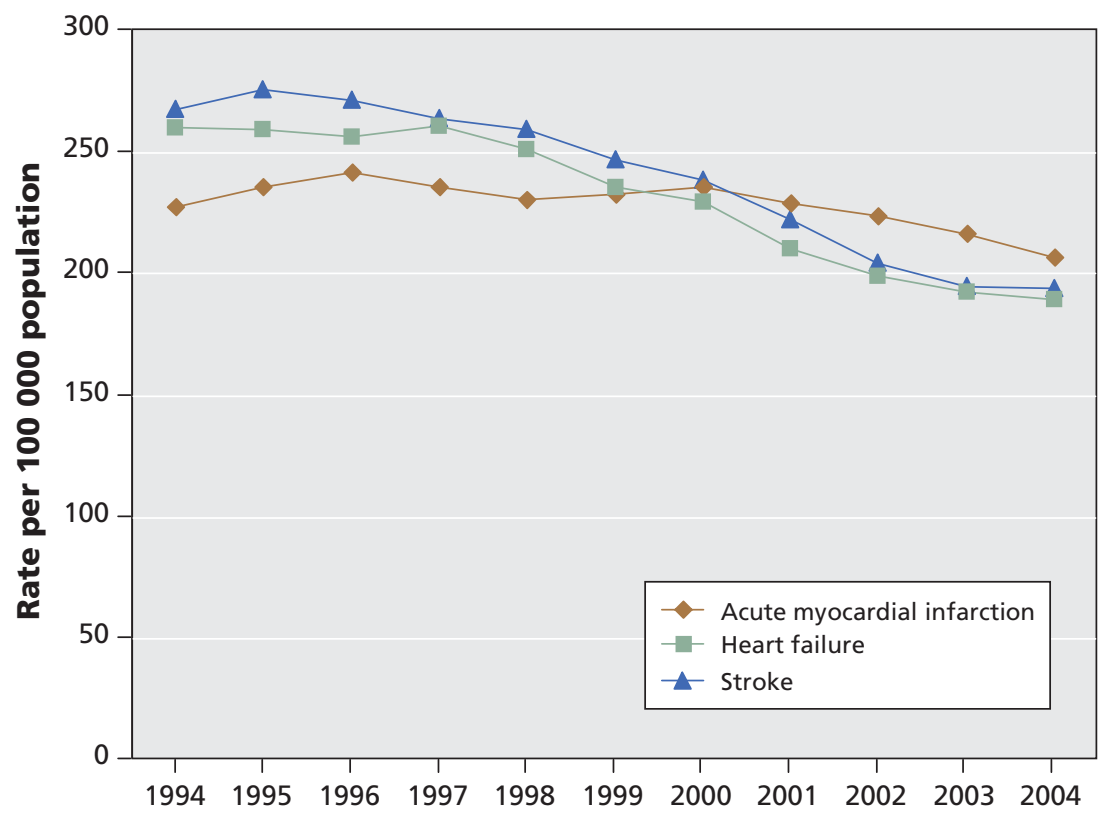

Figure 2: Age- and sex-standardized rates of hospital admissions because of acute myocardial infarction, heart failure and stroke per 100000 population aged 20 and over in Canada, 1994-2004. Rates are standardized to the Canadian 1991 census

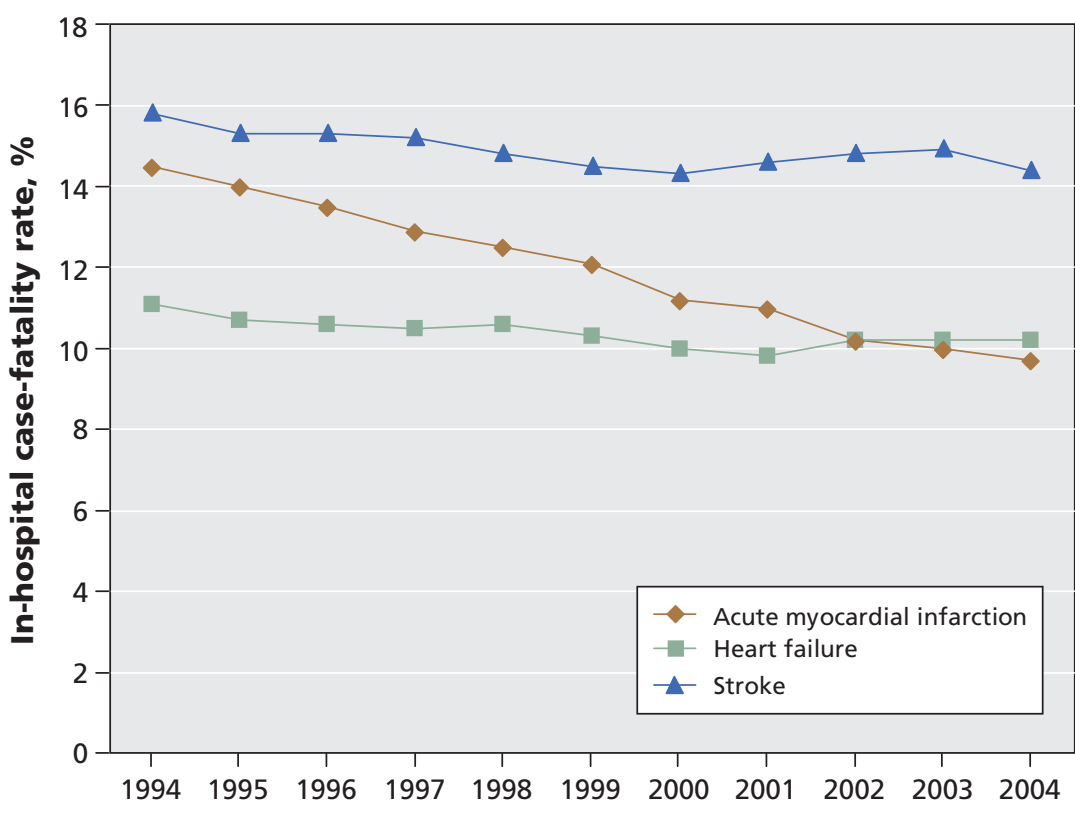

Figure 3: Age- and sex-adjusted in-hospital case-fatality rates among patients with acute myocardial infarction, heart failure and stroke in Canada, 1994-2004. Rates are standardized to the Canadian 1991 census population. 
troponin eras. These improvements probably reflect advances in treatment such as increased rates and timeliness of reperfusion therapy with primary angioplasty and fibrinolytic therapy along with increased use of acetylsalicylic acid, clopidogrel, $\beta$-blockers, angiotensin-converting-enzyme (ACE) inhibitors, angiotensin-receptor blockers and statins during the acute phase of myocardial infarction treatment, as has also been observed in other countries..$^{20}$

In contrast to acute myocardial infarction, the in-hospital case-fatality rate for stroke did not improve as much, although overall rates of death and hospital admissions because of stroke did decline significantly. Hypertension is the most important risk factor for stroke. During our study period, there were substantial increases in the use of antihyper- tensive medications such as diuretics, $\beta$-blockers, ACE inhibitors, angiotensin-receptor blockers and calcium-channel blockers in outpatients in Canada, along with the development of the Canadian Hypertension Education Program and better rates of hypertension control, as demonstrated in the Ontario Blood Pressure Prevalence Survey. ${ }^{18,21}$ A major advance in the in-hospital treatment of stroke during this period was the use of thrombolytic therapy for ischemic stroke. However, only a small proportion of all stroke patients receive thrombolytic therapy, the major benefit of which is improvement in functional status rather than a reduction in in-hospital mortality. ${ }^{22}$

Some studies have suggested a potential epidemic of heart failure because of the increasing elderly population and an in-

Table 3: Age- and sex-specific rates of hospital admissions by cardiovascular disease per 100000 population aged 20 and over in Canada, 1994-2004

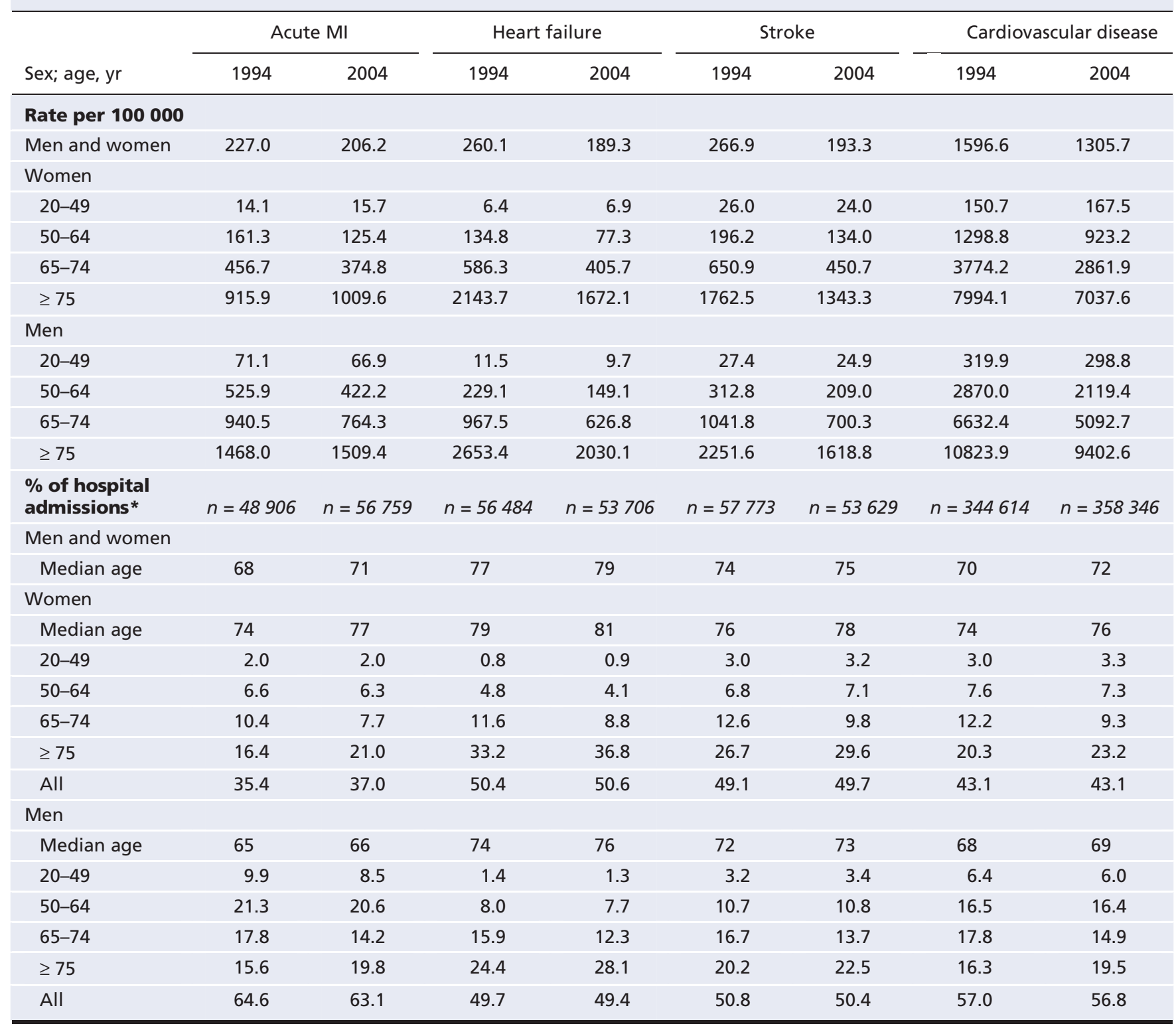

Note: $\mathrm{MI}=$ myocardial infarction.

*Unless stated otherwise. 
creasing number of people who survive acute myocardial infarction. ${ }^{23}$ The rate of hospital admissions because of heart failure has been steadily increasing in the United States, as compared with the decline we observed in Canada over similar periods. ${ }^{24}$ The reasons for this difference are unknown, but it could reflect in part a higher admission threshold for patients with heart failure in Canada, since inpatient bed resources are more limited and many beds were closed between 1994 and 2004.

Our finding that more women than men in Canada are dying of cardiovascular causes is noteworthy. Historically, cardiovascular disease was considered a problem of middle-aged men. Our analysis showed a high burden of death and hospital admission related to cardiovascular disease among elderly women. This highlights the need for increased investment in education and research on cardiovascular health and disease in women. Both the American Heart Association and the Heart and Stroke Foundation of Canada have started public education campaigns aimed at better informing women about the risk factors and symptoms of cardiovascular disease..$^{25,26}$

\section{Limitations}

Our study has important limitations. Few studies have validated the accuracy of codes for causes of death in death certificates in Canada. ${ }^{27}$ Validation studies conducted by the Framingham study investigators in the United States have shown that death certificates may be miscoded and may not correspond with the cause of death found at autopsy. ${ }^{28}$ Canada changed its coding system for death certificates from the ICD-9 to the ICD-10 coding system in 2000, which may have introduced a coding artifact. However, we did not detect any abrupt changes in the frequency of various causes of death after the introduction of the ICD-10 system, which suggests that this was not a major issue.

Another limitation was our inability to link the data on hospital admissions to the mortality data at a national level. Such a linkage would have enabled us to determine the exact proportion of in-hospital versus out-of-hospital deaths for all 3 conditions. It would have also allowed us to determine 30-day case-fatality rates in addition to in-hospital casefatality rates, which potentially are influenced by changes in length of stay after a hospitalization.

A final limitation was our inability to determine what proportion of hospital admissions were new versus repeat admissions. Although changes in the rates of hospital admissions probably reflect changes in the underlying incidence rates of disease, the determination of the true incidence of new events would best be done through labor-intensive chart reviews of deaths and admissions. However, this would be difficult to conduct at a national level because of the costs involved as well as privacy restrictions on data access.

\section{Conclusions}

We observed significant declines in population-based rates of death and hospital admissions for acute myocardial infarction, heart failure and stroke in Canada from 1994 to 2004. However, these findings are not grounds for compla- cency. Cardiovascular disease continues to be the leading cause of death and reason for hospital admissions in Canada. Our findings suggest that previous efforts to prevent cardiovascular events have been successful, but in many cases they may have delayed the occurrence of such events until people are older and potentially more difficult to treat. Further advances in prevention and treatment are required along with continued nationwide surveillance of cardiovascular events. The declines in mortality that we observed may plateau or even be reversed in the future because of increasing rates of key risk factors such as obesity and diabetes. ${ }^{29}$ The recent development of a national Canadian Heart Health Strategy (www.chhs-scsc.ca/web/) may serve to help facilitate coordinated efforts to reduce the burden of cardiovascular disease on the health of Canadians and the health care system.

Additional graphs and PowerPoint slides of data from this study are available for presentations at www.ccort.ca/Trends.aspx.

This article has been peer reviewed.

Competing interests: None declared.

Contributors: All of the authors contributed to the conception and design of the study, acquisition and interpretation of the data, and drafting and revising of the manuscript. All of the authors approved the final version submitted for publication.

Acknowledgements: We thank Tara O'Neill and Linda Donovan for their assistance in the preparation of this manuscript.

Parts of this material are based on data and information provided by the Canadian Institutes for Health Information. The analyses, conclusions, opinions and statements expressed are those of the authors and not necessarily those of the Canadian Institute for Health Information.

Funding: This study was supported by a Team Grant in Cardiovascular Outcomes Research to the Canadian Cardiovascular Outcomes Research Team (www.ccort.ca) from the Canadian Institutes of Health Research. Jack Tu is supported by a Canada Research Chair in Health Services Research, Ottawa, Ont., and by a Career Investigator Award from the Heart and Stroke Foundation of Ontario, Toronto, Ont.

The Institute for Clinical Evaluative Sciences is funded by an annual grant from the Ontario Ministry of Health and Long-Term Care. The opinions, results and conclusions reported in this paper are those of the authors and are independent from the funding sources. No endorsement by Institute for Clinical Evaluative Sciences or the Ontario Ministry of Health and LongTerm Care is intended or should be inferred.

\section{REFERENCES}

1. World Health Organization. World health statistics 2008. Geneva (Switzerland): The Organization; 2008. Available: www.who.int/whosis/whostat/EN_WHS08 _Full.pdf (accessed 2008 May 21).

2. Levi F, Lucchini F, Negri E, et al. Trends in mortality from cardiovascular and cerebrovascular diseases in Europe and other areas of the world. Heart 2002;88:119-24.

3. Fox CS, Evans JC, Larson MG, et al. Temporal trends in coronary heart disease mortality and sudden cardiac death from 1950 to 1999: the Framingham Heart Study. Circulation 2004;110:522-7.

4. Kannel WB. Incidence and epidemiology of heart failure. Heart Fail Rev 2000;5: 167-73.

5. Public Health Agency of Canada. Economic burden of illness in Canada, 1998. Ottawa (ON): The Agency; 1998. Available: www.phac-aspc.gc.ca/publicat /ebic-femc98/index-eng.php (accessed 2009 Mar. 26).

6. Vital Statistics - Death Database: detailed information for 2005. Ottawa (ON): Statistics Canada; 2007. Available: www.statcan.gc.ca/cgi-bin/imdb/p2SV.pl ?Function $=$ getSurvey $\&$ SurvId $=3233 \&$ SurvVer $=0 \&$ InstaId $=15306 \&$ InstaVer $=8 \&$ SDDS=3233\&lang=en $\& d b=i m d b \& a d m=8 \& d i s=2$ (accessed 2009 Mar. 26). 
7. International classification of diseases, 9th revision, clinical modification (ICD-9$C M$ ). Hyattsville (MD): US Department of Health and Human Services, Centers for Disease Control and Prevention, National Center for Health Statistics; 1988. Available: www.cdc.gov/nchs/about/otheract/icd9/abticd9.htm (accessed 2009 Mar. 26).

8. International statistical classification of diseases and related health problems, tenth revision (ICD-10-CM), 2009 update. Hyattsville (MD): US Department of Health and Human Services, Centers for Disease Control and Prevention, National Center for Health Statistics; 2009. Available: www.cdc.gov/nchs/about/otheract /icd9/icd10cm.htm (accessed 2009 May 11).

9. Kennedy CC, Brien SE, Tu JV. An overview of the methods and data used in the CCORT Canadian Cardiovascular Atlas project. Can J Cardiol 2003;19:655-63.

10. Austin PC, Daly PA, Tu JV. A multicenter study of the coding accuracy of hospita discharge administrative data for patients admitted to cardiac care units in Ontario. Am Heart J 2002;144:290-6.

11. Levy AR, Tamblyn RM, Fitchett D, et al. Coding accuracy of hospital discharge data for elderly survivors of myocardial infarction. Can J Cardiol 1999;15:1277-82.

12. Humphries KH, Rankin JM, Carere RG, et al. Co-morbidity data in outcomes research: Are clinical data derived from administrative databases a reliable alternative to chart review? J Clin Epidemiol 2000;53:343-9.

13. Rawson SB, Malcolm E. Validity of the recording of ischaemic heart disease and chronic obstructive pulmonary disease in the Saskatchewan health care datafiles. Stat Med 1995; 14:2627-43.

14. Mayo NE, Chockalingam A, Reeder BA, et al. Surveillance for stroke in Canada Health Rep 1994;6:62-72.

15. Canadian Institutes for Health Information. Inpatient hospitalizations for Canada (provinces and territories), 1995-1996, 2003-2004 and 2004-2005 [Table 1]. In Inpatient hospitalizations in Canada increase slightly after many years of decline. Ottawa (ON): The Institutes; 2005. Available: http://secure.cihi.ca/cihiweb/en /media_30nov2005_tab1_e.html (accessed 2008 Dec. 23).

16. Ford ES, Ajani UA, Croft JB, et al. Explaining the decrease in U.S. deaths from coronary disease, 1980-2000. N Engl J Med 2007;356:2388-98.

17. Canadian Tobacco Use Monitoring Survey (CTUMS) 2007. Ottawa (ON): Statistics Canada; 2008. Available: www.hc-sc.gc.ca/hl-vs/tobac-tabac/researchrecherche/stat/ctums-esutc 2007-eng.php (accessed 2008 Dec. 18).

18. Jackevicius CA, Tu K, Filate WA, et al. Trends in cardiovascular drug utilization and drug expenditures in Canada between 1996 and 2001. Can J Cardiol 2003;19:1359-66.

19. Joint European Society of Cardiology/American College of Cardiology Committee. Myocardial infarction redefined: a consensus document of the Joint European Society of Cardiology/American College of Cardiology committee for the redefinition of myocardial infarction. Eur Heart J 2000;21:1502-13.

20. Fox KA, Steg PG, Eagle KA, et al. Decline in rates of death and heart failure in acute coronary syndromes, 1999-2006. JAMA 2007;297:1892-900.

21. Leenen FH, Dumais J, McInnis NH, et al. Results of the Ontario survey on the prevalence and control of hypertension. CMAJ 2008;178:1441-9.

22. National Institute of Neurological Disorders and Stroke rt-PA Stroke Study Group. Tissue plasminogen activator for acute ischemic stroke. N Engl J Med 1995;333:1581-8.

23. Velagaleti RS, Pencina MJ, Murabito JM, et al. Long-term trends in the incidence of heart failure after myocardial infarction. Circulation 2008;118:2057-62.

24. Rosamond W, Flegal K, Furie K, et al. Heart disease and stroke statistics - 2008 update: a report from the American Heart Association Statistics Committee and Stroke Statistics Subcommittee. Circulation 2008;117:e25-146.

25. American Heart Association. Go red for women - untold stories of the heart. Dallas (TX): The Association; 2008. Available: www.goredforwomen.com/index.aspx (accessed 2008 Dec. 23).

26. Heart and Stroke Foundation. The Heart Truth Campaign. Ottawa (ON): The Foundation. Available: www.thehearttruth.ca/the_campaign/(accessed 2008 Dec. 23).

27. Guibert RL, Wigle DT, Williams JI. Decline of acute myocardial infarction death rates not due to cause of death coding. Can J Public Health 1989;80:418-22.

28. Lloyd-Jones DM, Martin DO, Larson MG, et al. Accuracy of death certificates for coding coronary heart disease as the cause of death. Ann Intern Med 1998;129:1020-6.

29. Ford ES, Capewell S. Coronary heart disease mortality among young adults in the U.S. from 1980 through 2002: concealed leveling of mortality rates. J Am Coll Cardiol 2007;50:2128-32.

Correspondence to: Dr. Jack V. Tu, Senior Scientist, Institute for Clinical Evaluative Sciences, Rm. G106, 2075 Bayview Ave., Toronto ON M4N 3M5; fax 416 480-6048; tu@ices.on.ca

\section{The Canadian Cardiovascular Outcomes Research Team:}

Jack V. Tu MD MSc PhD, Institute for Clinical Evaluative Sciences, Sunnybrook Health Sciences Centre, University of Toronto; William Ghali MD MPH, University of Calgary; Louise Pilote MD MPH PhD, Division of General Internal Medicine, McGill University and McGill University Health Centre; Jafna L. Cox BA MD, Division of Cardiology, Dalhousie University, Capital Health; Douglas S. Lee MD PhD, Institute for Clinical Evaluative Sciences, Division of Cardiology, Toronto General Hospital; Karin H. Humphries MBA DSc, University of British Columbia, Division of Cardiology; David Alter MD PhD, Institute for Clinical Evaluative Sciences, Division of Cardiology, St. Michael's Hospital and the Toronto Rehabilitation Institute; Peter C. Austin PhD, Institute for Clinical Evaluative Sciences, Dalla Lana School of Public Health, University of Toronto; Mark J. Eisenberg MD MPH, Divisions of Cardiology and Clinical Epidemiology Jewish General Hospital, McGill University; William M. Flanagan BM, Statistics Canada; P. Diane Galbraith BN MSc, Foothills Medical Centre, University of Calgary; Michelle M. Graham MD, University of Alberta; Ansar Hassan MD PhD, Department of Cardiac Surgery, Saint John Regional Hospital, Atlantic Health Sciences Corporation; Gregory M. Hirsch MD, Department of Surgery, Dalhousie University; Thao Huynh MD MSc, Research Institute of the McGill University Health Centre; Cynthia A. Jackevicius BScPhm PharmD MSc, Western University of Health Sciences, Institute for Clinical Evaluative Sciences; Helen L. Johansen PhD, Health Analysis Division, Statistics Canada, Department of Community Medicine and Epidemiology, University of Ottawa; Merril L. Knudtson MD, Libin Cardiovascular Institute of Alberta; Dennis T. Ko MD MSc, Division of Cardiology, Schulich Heart Centre, Sunnybrook Health Sciences Centre, University of Toronto, Institute for Clinical Evaluative Sciences; Michael P. Love MB ChB MD, Department of Medicine, Queen Elizabeth II Health Sciences Centre, Dalhousie University; Doug Manuel MD MSc, Ottawa Health Research Institute; Colleen M. Norris, RN PhD (Epid), Faculties of Nursing and Medicine, University of Alberta; Wayne Putnam MD,

Department of Family Medicine, Dalhousie University; Stéphane Rinfret MD SM, Institut Universitaire de Cardiologie et de Pneumologie de Québec, Université Laval; Michael J. Schull MD MSc, Institute for Clinical Evaluative Sciences, Department of Medicine, University of Toronto; Derek Y. So MD, University of Ottawa Heart Institute; Therese A. Stukel PhD, Institute for Clinical Evaluative Sciences; Lawrence W. Svenson BGS DipPsych, Surveillance and Environmental Health, Alberta Health and Wellness, School of Public Health, University of Alberta; Christopher R. Thompson MD CM, St. Paul's Hospital, University of British Columbia; Karen Tu MD MSc, Institute for Clinical Evaluative Sciences, Department of Family and Community Medicine, University of Toronto; and Nancy A. Walton PhD, Daphne Cockwell School of Nursing Chair, Research Ethics Board, Ryerson University. 